\title{
Multi-resistance to thiophanate-methyl, diethofencarb, and procymidone among Alternaria alternata populations from tobacco plants, and the management of tobacco brown spot with azoxystrobin
}

\author{
H. C. Wang - C. Q. Zhang
}

Received: 11 May 2018 / Accepted: 20 August 2018/Published online: 27 August 2018

(C) Springer Nature B.V. 2018

\begin{abstract}
In 2014 and 2015, a total of 151 tobacco brown spot (Alternaria alternata) isolates were collected from Guizhou Province in China to evaluate their resistance to the benzimidazole thiophanate-methyl, the carbamate diethofencarb, and the dicarboximide procymidone. Resistance to thiophanate-methyl and diethofencarb was observed in all isolates. Resistance to all the three fungicides, thiophanate-methyl, diethofencarb, and procymidone was detected at a frequency of $6.0 \%$. The F167Y single mutation in the $\beta$ tubulin gene was found to be associated with resistance to thiophanate-methyl,but no mutation was found in the coiled-coil region of the histidine kinase-encoding gene OS1, a fungal gene for dicarboximide resistance. Procymidone applied at the rate of $20 \mathrm{mg} \mathrm{l}^{-1}$ inhibited spot lesion formation on tobacco leaves with an efficacy of $51.7 \%$ for the low resistance (LR) isolates and $74.2 \%$ for the procymidone-sensitive isolates. Thiophanatemethyl applied at $100 \mathrm{mg} \mathrm{l}^{-1}$, however, slightly promoted the expansion of disease lesions with an efficacy of $-7.7 \%$. Azoxystrobin applied at 10 and $20 \mathrm{mg}^{-1}$ provided efficacies of 91.1 and $100 \%$, respectively, regardless of whether the isolates were thiophanate-methyl resistant or procymidone-LR. Further studies suggested that azoxystrobin exhibited excellent protective activity
\end{abstract}

H. C. Wang

Guizhou Academy of Tobacco Science, Guiyang 550081, China

H. C. Wang · C. Q. Zhang $(\bowtie)$

Department of Crop Protection, Zhejiang Agriculture and Forest University, Lin'an 311300, China

e-mail: cqzhang9603@126.com and good curative activity against $A$. alternata in plants. The baseline sensitivity to azoxystrobin was then determined. In the presence SHAM, the mean $\mathrm{EC}_{50}$ values for conidial germination inhibition were $0.49 \pm 0.22$ (Mean $\pm \mathrm{SD}$ ) $\mathrm{mg} \mathrm{l}^{-1}$. Interestingly, no resistance was recovered through UV irradiation or Agrobacterium tumefaciens-mediated mutagenesis. This research indicated widespread resistance to thiophanate-methyl and diethofencarb, low frequency of $(6.0 \%)$ resistance to procymidone in A. alternata populations from tobacco, and suggested that azoxystrobin could potentially constitute a good alternative for the management of tobacco brown spot disease.

Keywords Alternaria alternata . Tobacco brown spot . Benzimidazole fungicides; dicarboximide fungicides . Azoxystrobin - Fungicide resistance and management . Baseline sensitivity

\section{Introduction}

Alternaria alternata (Fr.) Keissl. is an important plantpathogenic fungus that has at least seven pathotypes, including one that affects tobacco (Nishimura and Kohmoto 1983). The brown spot (TBS) disease caused by A. alternata is a significant foliar disease that limits tobacco production worldwide (Cheng et al. 2011; Stavely 1975). The fungus mainly infects the leaves of tobacco, although the stems, pedicels, and capsules may also be damaged in severe cases (Lucas 1975; Shew and Lucas 1991). In China, the disease can rapidly infect 
tobacco plants during its short incubation period under optimal conditions, thereafter spreading swiftly. In the main tobacco production zones of southwestern China, such as Guizhou and Yunnan Province, TBS has resulted in annual losses of between 25 and 50\% (Dong et al. 2009; Xu et al. 2011). The application of fungicides is the primary method for the management of TBS. Dicarboximide fungicides (FRAC [Fungicide Resistance Action Committee] code 2) and benzimidazole fungicides (FRAC 1) have been widely applied in tobacco production in China for more than 20 years (Dong et al. 2009; Li et al. 2002). Decreased efficacy, or even failure, of these fungicides to control TBS has frequently been recorded in recent years, but no reasonable scientific data explaining this phenomenon exists (Zhang et al. 2013a, b). No comprehensive assessment of the resistance of TBS to fungicides has been performed.

Although several laboratory mutants of fungi such as Sclerotinia sclerotiorum displaying high levels of resistance to dicarboximide fungicides that interfere with the osmotic signal transduction in fungi (Firoz et al. 2016; Ma and Michailides 2005) have been described, only a few resistant isolates have been reported in the field. Furthermore, point mutations in the histidine kinase-encoding gene $(O S)$ are considered to be the cause of resistance to dicarboximide fungicides. However, the molecular resistance mechanisms have not yet been fully elucidated (Avenot et al. 2005; Firoz et al. 2016). Therefore, unknown mechanisms that are not yet discovered could be involved in the occurrence of dicarboximide resistance.

Benzimidazole fungicides consist of chemicals that bind to $\beta$-tubulin and inhibit nuclear division in fungi (Davidson et al. 2006). Generally, resistance to benzimidazole fungicides is associated with single-point mutations that are restricted to codon positions 50, 198, 200, and 240 (Ma and Michailides 2005; Torres-Calzada et al. 2015; Zhang et al. 2010) in the $\beta$-tubulin gene. In plant pathogenic fungi, Ben R2 (double-resistant to benzimidazole fungicides and diethofencarb[FRAC 10]) isolates of Botrytis cinerea with a point mutation at codon 200 are commonly observed in the field after the application of a mixture of "a benzimidazole fungicide + diethofencarb" to control Ben R1. The latter (Ben R1) generally possess a mutation at codon 198, which is associated with high resistance to benzimidazole fungicides but sensitivity to diethofencarb (Fan et al. 2015; Leroux et al. 2002; Lin et al. 2016; Nenad et al. 2015).

QoI ( $Q_{0}$ inhibitor) compounds (FRAC 11), which inhibit mitochondrial electron transport in fungi through binding to the quinol oxidation $\left(\mathrm{Q}_{\mathrm{O}}\right)$ site of cytochrome $\mathrm{b}$, have become the major fungicide group in some plants during the past decade (Bartlett et al. 2002; Estep et al. 2015; Karaoglanidis et al. 2011; Vega et al. 2012). Q $Q_{\mathrm{O}}$ Is have activity towards nearly all important taxonomic groups, i.e., Ascomycota, Basidiomycota, Deuteromycota, and Oomycota (Drabesova et al. 2013; Fairchild et al. 2013). However, little information is available regarding the efficacy of $\mathrm{Q}_{\mathrm{O}}$ Is against A. alternata from tobacco plants. The present research was thus conducted to: (i) detect the resistance occurrence to dicarboximide and benzimidazole fungicides within A. alternata populations from tobacco crops in China; (ii) investigate the association of mutations in the two-component histidine kinase gene and $\beta$-tubulin gene with the resistance of $A$. alternata to dicarboximide and benzimidazole fungicides, respectively; (iii) assess the activity of azoxystrobin against TBS; and (iv) determine the baseline sensitivity to azoxystrobin of the A. alternata populations from tobacco.

\section{Materials and methods}

\section{Fungicides}

For the in vitro evaluations, $97 \%$ thiophanate-methyl (Zhejiang Welldone Chemistry Company, Hangzhou, China), $98.1 \%$ procymidone (Zhejiang Welldone Chemistry Company, Hangzhou, China), 96\% diethofencarb (Zhejiang Welldone Chemistry Company, Hangzhou, China), and $98.7 \%$ azoxystrobin (Syngenta, Beijing, China) were used. All the technical grade fungicides were separately dissolved in acetone (Sangon, Shanghai, P. R. China) to obtain stock solutions, which were kept at $4{ }^{\circ} \mathrm{C}$ in the dark. Formulated products, namely $70 \%$ thiophanate-methyl WP (Zhejiang Welldone Chemistry Company, Hangzhou, China), 50\% diethofencarb WP (Zhejiang Welldone Chemistry Company, Hangzhou, China), 50\% procymidone WP (Guoguang Agrichemical Company, Sichuan, China), and 25\% azoxystrobin SC (Amistar, Syngenta, Beijing, China) were adopted for the plant tests.

\section{Collection and culture of isolates}

Isolates (Fig. 1) from diseased tobacco plants were collected in 2014 and 2015 from Xinquan (XQ) and Xingyi (XY), which are the main tobacco production regions of Guizhou Province (Table 1) with no history of the use of 


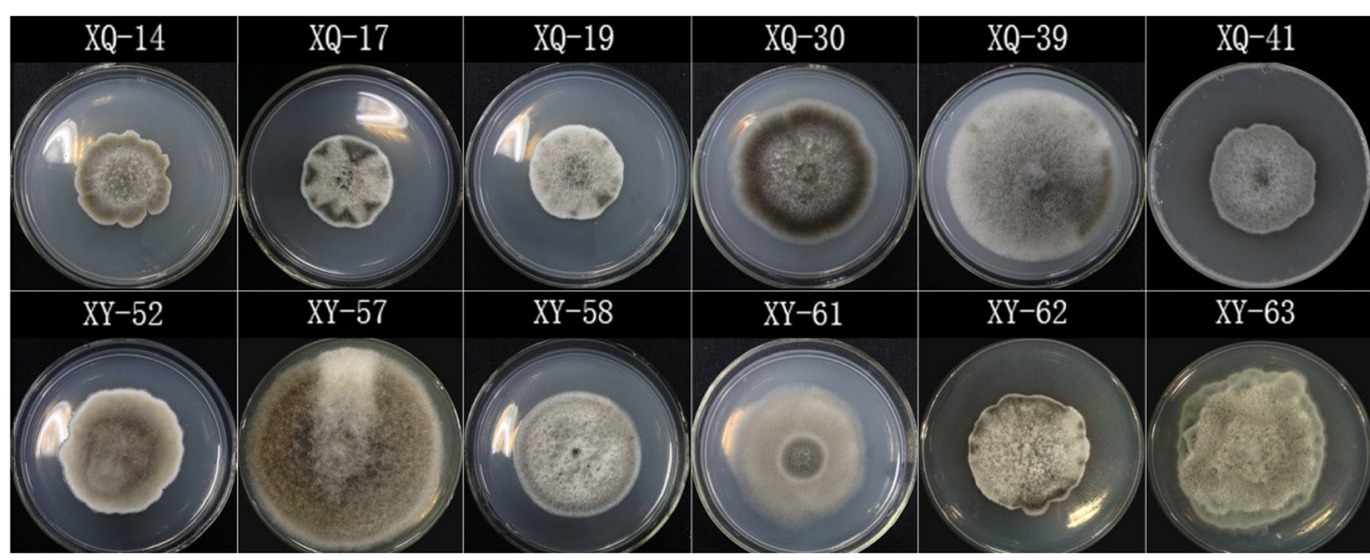

\begin{tabular}{|c|c|c|c|c|c|}
\hline $\mathrm{XQ}-14$ & $\mathrm{XQ}^{-17}$ & $\mathrm{XQ}-19$ & $\mathrm{XQ}^{-}-30$ & $\mathrm{XQ}-39$ & $X Q-41$ \\
\hline 8 & & & 8 & & $\int_{-\infty}^{8}$ \\
\hline$X Y-52$ & $X Y-57$ & XY-58 & $\mathrm{XY}-61$ & $X Y-62$ & $X Y-63$ \\
\hline 8 & $A$ & 8 & 8 & 8 & 8 \\
\hline
\end{tabular}

Fig. 1 Characteristics of the colonies and conidial chain's morphology of isolates of $A$. alternata causing tobacco brown spot

QoIs. In total, 151 single-conidial A. alternata isolates were isolated from 28 tobacco fields that had been treated annually with dicarboximide and benzimidazole fungicides for more than 15 years. The fields were located at least $15 \mathrm{~km}$ away from each other. Then, all isolates were identified through morphology, DNA sequence analysis of the internal transcribed spacer (ITS) region, and the pathogenicity on the tobacco plants. All the isolates were maintained on potato dextrose agar (PDA) slants in a $4{ }^{\circ} \mathrm{C}$ refrigerated cabinet.
Assessment of the resistance to thiophanate-methyl, diethofencarb, and procymidone

Resistance to thiophanate-methyl, diethofencarb, and procymidone was determined by measuring the radial growth on PDA medium amended with $0,0.025,0.05$, $1,5,20,50$, and $100 \mathrm{mg}$ active ingredient (ai) $\mathrm{l}^{-1}$ of each fungicide (Zhang et al. 2010). Fungicide was added to the medium after sterilization. Mycelial plugs (5 $\mathrm{mm}$ in diameter) from the five-day-old colony of A. alternata on PDA

Table 1 Number of isolates of A. alternata in tobacco that are resistant to thiophanate-methyl, diethofencarb, and procymidone

\begin{tabular}{llllll}
\hline \multirow{2}{*}{ Fungicide } & \multicolumn{2}{l}{ Xinquan, Guizhou Province } & & & \multicolumn{2}{c}{ Xingyi, Guizhou Province } \\
\cline { 5 - 6 } & Sensitive & Resistant & & Sensitive & Resistant \\
\hline Thiophanate-methyl+Diethofencarb & 0 & 72 & 0 & 79 \\
Procymidone & 66 & 6 & 6 & 76 & 3 \\
Thiophanate-methyl+Diethofencarb+procymidone & 66 & & 76 & 3 \\
\hline
\end{tabular}


were placed into the center of the plates. For each treatment, three PDA plates were used. After incubation for six days in the dark at $25^{\circ} \mathrm{C}$, the diameter of each colony was measured (Fairchild et al. 2013). The mean of the diameters was adopted to determine the $\mathrm{EC}_{50}$ that inhibited radial mycelial growth by 50\% (Chen et al. 2015; Vitale et al. 2016). The sensitive (S) isolates had a minimum inhibitory concentration (MIC) $<5 \mathrm{mg} \mathrm{l}^{-1}$ with an $\mathrm{EC}_{50}<1 \mathrm{mg} \mathrm{l}^{-1}$. The isolates of low resistance (LR) and moderate resistance (MR) had: $5 \mathrm{mg} \mathrm{l}^{-1}<\mathrm{MIC}<20 \mathrm{mg} \mathrm{l}^{-1}$ and $50 \mathrm{mg} \mathrm{l}^{-1}$ $<$ MIC $<100 \mathrm{mg} \mathrm{l}^{-1}$, respectively. The isolates of high resistance (HR) could grow on PDA plates amended with $100 \mathrm{mg} \mathrm{l}^{-1}$ thiophanate-methyl, diethofencarb, or procymidone, and had $\mathrm{EC}_{50}$ values $>50 \mathrm{mg} \mathrm{l}^{-1}$ (Chen et al. 2007; Maymon et al. 2006; Torres-Calzada et al. 2015).

Isolation of the $\beta$-tubulin and OS1 gene fragments

In this study, 10 isolates from different fields were arbitrarily selected in order to analyze the gene fragments, including the 198th and 200th codon of $\beta$ tubulin, with the primer pair Bt2a (5-GGTAACCA AATCGGTGCTGCTTTC-3) and btu2r (5AGTtGGGACAGCCATCATGT-3) (Fan et al. 2015). DNA was extracted from isolates that had been incubated on PDA for six days in the dark using the SK1204 kit according to the protocol. The primer pair of AaHKF (5-GCACTGCGGGAAATCGGC-3) and AaHKR (5-GCTTCCCTCGCAGCCGTG-3) (Ma et al. 2005) was used to amplify the coiled-coil region of OS1 for all procymidone-resistant isolates as well as 10 arbitrarily selected procymidone-sensitive isolates. The PCR products were assessed using electrophoresis and then purified with the SK1131 kit according to the instructions. The molecular kits were purchased from Sangon Company, Shanghai, China. Sequencing of the amplified PCR products was completed by Invitrogen (Shanghai, China). Alignment and analysis were carried out using Clustal W.

Control of A. alternata in tobacco plants

Seven isolates collected from the tobacco fields of Guizhou Province in China, including four procymidoneLR isolates and three procymidone-S isolates, were arbitrarily selected for the assays. The tobacco (cultivar Zhongyan 100) was planted in greenhouses under normal agronomic practices. When the plants had nine true leaves, they were sprayed with fungicide $12 \mathrm{~h}$ prior to inoculation with A. alternata as follows: (A) $70 \%$ thiophanate-methyl WP at a concentration of $100 \mathrm{mg}$ ai $1^{-1}$, (B) $70 \%$ thiophanate-methyl WP (100 mg ai $\mathrm{l}^{-1}$ ) $+50 \%$ diethofencarb WP (100 mg ai $\mathrm{l}^{-1}$ ), (C) $50 \%$ procymidone WP (20 $\mathrm{mg}_{\text {ai }} \mathrm{l}^{-1}$ ), (D) $25 \%$ azoxystrobin SC (10 $\mathrm{mg}$ ai $\left.\mathrm{l}^{-1}\right)$, (E) 25\% azoxystrobin SC (20 mg ai $1^{-1}$ ), and (F) sterilized distilled water that contained Tween 80 without any fungicide (SDW), which was used as the control (CK). The fungicides were applied using the WS-6 backpack sprayer (Weishi Plant Protection Company, Qingdao, China). The inoculations of A. alternata were performed using the detached tobacco leaf method (Xu et al. 2011). Briefly, the third and the fourth leaves of each tobacco plant were harvested and then inoculated with suspensions at a concentration of $3 \times 10^{4}$ conidia per ml containing Tween 80 . Following the inoculations, the leaves were placed into Petri dishes containing two layers of filter paper and incubated for $24 \mathrm{~h}$ in the dark at $28{ }^{\circ} \mathrm{C}$ with $96 \%$ relative humidity (RH). Then, all Petri dishes containing inoculated leaves were maintained at $26{ }^{\circ} \mathrm{C}$ with a $12 \mathrm{~h} / 12 \mathrm{~h}$ (light/dark) cycle and $90 \% \mathrm{RH}$. The treatments were repeated in triplicate, and each repeat included 10 leaves using a randomized complete block design. Ten days after the inoculations of $A$. alternata, the expansion of the TBS disease lesions was determined. The mean diameters of the lesions were calculated and represented the expansion of the lesions for each treatment. Percentage $(\%)$ of efficacy inhibiting lesion diameter $=100 \times(\mathrm{CK}$-a treatment)/CK. Data analysis was performed using SAS version 9.1 (SAS Institute, USA). Data were assessed for normality and homogeneity of variance, and an arcsine transformation was performed only if necessary. The data were subsequently analyzed using analysis of variance (ANOVA). Treatment means were differentiated using least significant difference (LSD) tests $(p=$ 0.05 ) and the means of efficacy were back-transformed.

Evaluation of the protective and curative activity of azoxystrobin

The same seven isolates were used. Tobacco plants with nine true leaves were sprayed with $0.1,1,10$, and $20 \mathrm{mg}$ ai $\mathrm{l}^{-1}$ of azoxystrobin. Azoxystrobin treatments were carried out $0 \mathrm{~h}, 12 \mathrm{~h}$, and $24 \mathrm{~h}$ before inoculation and $48 \mathrm{~h}$ after inoculation to estimate the protective and curative activity, respectively (Chen et al. 2015). SDW was adopted as the CK. All other experimental details were the same as above. 
Assessment of the effect of azoxystrobin on mycelial growth with or without salicylhydroxamic acid (SHAM)

The same seven isolates were used for the determination of the inhibitory activity of azoxystrobin towards the mycelial growth of $A$. alternata in vitro. PDA plates amended with $0,0.1,1,5,10,20,50,100$, and $200 \mathrm{mg}$ ai $1^{-1}$ of azoxystrobin were used. Evaluations were performed in the presence of 0 and $50 \mathrm{mg}^{-1}$ SHAM (Drabesova et al. 2013), as described by Zhang et al. (2011). The experiment was repeated twice, and three PDA plates were adopted for each azoxystrobin concentration. Data were normalized by logarithmic transformation and the $\mathrm{EC}_{50}$ values inhibiting the mycelial growth of A. alternata from tobacco were calculated using a linear regression equation. The goodness-of-fit for the regression was assessed by the $\mathrm{R}^{2}$ value. Inhibition of the different isolates was analyzed by ANOVA, and the mean $\mathrm{EC}_{50}$ values were compared through LSD tests $(P=0.05)$. Homogeneity of variance between the two tests was carried out through a Bartlett's test prior to ANOVA (Pitt et al. 2012). $\log _{10}$ transformed data was used, and the means of the $\mathrm{EC}_{50}$ values were back-transformed.

Establishment of the sensitivity baseline to azoxystrobin

Each of the 151 isolates was cultured for $6 \mathrm{~d}$ on PDA plates at $25^{\circ} \mathrm{C}$, and conidial suspensions $\left(10^{4}\right.$ conidia per liter) were prepared. The serial treatment concentrations were $0,0.04,0.08,0.16,0.32,0.64,1.28$, and $2.56 \mathrm{mg}$ ai $1^{-1}$ of azoxystrobin. Each $0.2 \mathrm{ml}$ conidial suspension was poured onto the surface of a $2.0 \%$ water agar (WA) plate amended with azoxystrobin and $50 \mathrm{mg}$ ai $1^{-1}$ SHAM (Avila-Adame and Köller 2003), as described by Zhang et al. (2011). The conidia were then allowed to germinate. At this point, the experiment was carried out twice and each concentration of azoxystrobin had three repeats. The germination was estimated under an optical microscope, as described by Zhang et al. (2011), after incubation for $14 \mathrm{~h}$ at $25^{\circ} \mathrm{C}$ in the dark. For each of the isolates, the $\mathrm{EC}_{50}$ was calculated using linear regression. The goodness-of-fit for the regression was assessed based on the $\mathrm{R}^{2}$ value. The baseline sensitivities of all isolates to azoxystrobin were thus determined. A histogram of the frequency of the $\mathrm{EC}_{50}$ values was analyzed, as previously described (Russell 2004; Zhang et al. 2013a, b).
In vitro induction of azoxystrobin resistance

Induction of azoxystrobin resistant mutants was carried out using two methods. For UV irradiation, $1 \times$ $10^{6}$ conidia were spread onto PDA plates supplemented with $10 \mathrm{mg}$ ai $1^{-1}$ azoxystrobin and $50 \mathrm{mg}$ ai $1^{-1}$ SHAM, after which they were exposed to UV light for $0,1,3$ and $20 \mathrm{~min}$. Following UV radiation, the plates were incubated at $25^{\circ} \mathrm{C}$ for $7 \mathrm{~d}$, and all colonies were transferred to PDA plates containing $10 \mathrm{mg}$ ai $\mathrm{l}^{-1}$ azoxystrobin and $50 \mathrm{mg}$ ai $\mathrm{l}^{-1}$ SHAM. After $7 \mathrm{~d}$, the colonies that had grown on the PDA containing $10 \mathrm{mg}$ ai $\mathrm{l}^{-1}$ azoxystrobin and $50 \mathrm{mg}$ ai $\mathrm{l}^{-1}$ SHAM were identified as the azoxystrobin-resistant phenotype. Azoxystrobin resistant mutants were also induced by Agrobacterium tumefaciens-mediated mutation: $1 \times 10^{6}$ conidia, and A. tumefaciens $(\mathrm{OD}=$ $0.7)$ were spread onto induction medium (IM) plates covered with nitrocellulose filter and incubated at $23{ }^{\circ} \mathrm{C}$ for $48 \mathrm{~h}$. Then, the nitrocellulose filter was transferred onto culture medium (CM) plates supplemented with $250 \mathrm{mg}$ ai $\mathrm{l}^{-1}$ tetracycline, $250 \mathrm{mg}$ ai $\mathrm{l}^{-1}$ cefotaxime, and $47 \mathrm{mg}$ ai $\mathrm{l}^{-1}$ hygromycin $\mathrm{B}$ and incubated at $28{ }^{\circ} \mathrm{C}$ for $5 \mathrm{~d}$. All colonies were transferred to PDA plates containing $10 \mathrm{mg}$ ai $1^{-1}$ azoxystrobin and $50 \mathrm{mg}$ ai $1^{-1}$ SHAM. After $7 \mathrm{~d}$, the colonies that had grown on the CM containing $10 \mathrm{mg}$ ai $\mathrm{l}^{-1}$ azoxystrobin and $50 \mathrm{mg}$ ai $\mathrm{l}^{-1}$ SHAM were identified as azoxystrobin-resistant phenotypes.

\section{Results}

Resistance to thiophanate-methyl, diethofencarb, and procymidone

The A. alternata isolates $(n=151)$ from the tobacco plants differed in colony characteristics and growth rates but all produced branched and long conidial chain each with more than five conidia (Fig. 1). All the isolates tested ( $\mathrm{n}=151)$ exhibited HR to thiophanate-methyl and diethofencarb (Table 1). Additionally, nine isolates with LR to procymidone $\left(5 \mathrm{mg} \mathrm{l}^{-1}<\mathrm{MIC}<20 \mathrm{mg} \mathrm{l}^{-1}\right.$ ) were detected with a frequency of $6.0 \%$. Among these LR isolates, six were collected from Xinquan and three were collected from Xinyi (Table 1). Triple resistance of A. alternata to thiophanate-methyl, diethofencarb, and procymidone was detected for the first time with a frequency of $6.0 \%$ (Table 1 ). 
Point mutations in the $\beta$-tubulin and OS1 genes of $A$. alternata from tobacco

In the present research, the amplified sequence of $\beta$ tubulin of A. alternata included the codons that were previously reported to cause resistance to thiophanatemethyl. Only a single F167Y mutation was observed in all of the HR isolates. No mutation was found in $\mathrm{OS} 1$ for all nine procymidone-LR isolates.

\section{Control of A. alternata in tobacco}

Procymidone $\left(20 \mathrm{mg} \mathrm{l}^{-1}\right)$ inhibited spot lesion formation on the tobacco leaves with an efficacy of $51.7 \%$ for the procymidone-LR isolates and $74.2 \%$ for the procymidone-S isolates (Table 2). Thiophanate-methyl (100 mg $\left.\mathrm{m}^{-1}\right)$, however, slightly promoted the expansion of disease lesions for all of the seven HR isolates tested, indicating a control efficacy of $-3.6 \%$ to $-12.6 \%$ with a mean of $-7.7 \%$. Such a phenomenon was not observed for "thiophanate-methyl + diethofencarb", which provided poor control against $A$. alternata with an efficacy of 3.7 to $8.2 \%$ and a mean of $5.9 \%$ (Table 2). When applied $12 \mathrm{~h}$ prior to inoculation, however, azoxystrobin provided good control regardless of whether the isolates were thiophanate-methyl-HR or procymidone-LR. At $10 \mathrm{mg} \mathrm{l}^{-1}$, azoxystrobin had a mean control efficacy of $91.1 \%$. Additionally, $20 \mathrm{mg} \mathrm{l}^{-1}$ azoxystrobin completely prevented the formation of disease lesions on the tobacco leaves by A. alternata with $100 \%$ efficacy (Table 2).

Protective and curative activity for A. alternata inoculation

When the concentrations were $\geq 10 \mathrm{mg}^{-1}$, azoxystrobin had a strong inhibitory action against the expansion of disease lesions in the leaves of tobacco by A. alternata, regardless of whether the fungicide treatments were performed 12 and $24 \mathrm{~h}$ before or $48 \mathrm{~h}$ after the fungal inoculations. However, at concentrations of $\leq 1 \mathrm{mg} \mathrm{l}^{-1}$, azoxystrobin exhibited stronger inhibition on disease lesion development when the fungicide treatments were performed 12 and $24 \mathrm{~h}$ before inoculation than $48 \mathrm{~h}$ after the inoculation of $A$. alternata (Fig. 2).

Synergy between azoxystrobin and SHAM in mycelial growth inhibition

Azoxystrobin demonstrated low inhibitory activity on the growth of A. alternata from tobacco. In the absence of SHAM, a specific inhibitor of alternative oxidase, the mean $\mathrm{EC}_{50}$ values of the seven isolates were as high as $79.97 \mathrm{mg} \mathrm{l}^{-1}$, whereas the $\mathrm{EC}_{50}$ value in the presence of $50 \mathrm{mg}^{-1}$ SHAM was

Table 2 Control of A. alternata in tobacco by thiophanate-methyl, diethofencarb, procymidone, and azoxystrobin applied $12 \mathrm{~h}$ before inoculation

\begin{tabular}{|c|c|c|c|c|c|c|}
\hline \multirow[t]{2}{*}{ Isolates } & \multirow[t]{2}{*}{ Phenotypes $^{\mathrm{X}}$} & \multicolumn{5}{|c|}{ Inhibition percentage $(\%)$ of lesion diameter ${ }^{Z}$} \\
\hline & & Thi & Thi + Die & Pro & Azo 10 & Azo 20 \\
\hline XQ-3 & Thi HR, Die HR, Pro LR & $-3.6 b^{Y}$ & $4.6 \mathrm{a}$ & $55.7 \mathrm{~b}$ & $89.2 \mathrm{a}$ & $100.0 \mathrm{a}$ \\
\hline XQ-7 & & $-5.4 \mathrm{~b}$ & $3.7 \mathrm{a}$ & $51.8 \mathrm{~b}$ & $93.5 \mathrm{a}$ & $100.0 \mathrm{a}$ \\
\hline XY-5 & & $-10.3 \mathrm{a}$ & $5.9 \mathrm{a}$ & $48.9 \mathrm{~b}$ & $87.6 \mathrm{a}$ & $100.0 \mathrm{a}$ \\
\hline$X Y-13$ & & $-5.9 b$ & $5.4 \mathrm{a}$ & $50.3 b$ & $95.4 \mathrm{a}$ & $100.0 \mathrm{a}$ \\
\hline$X Y-25$ & Thi HR, Die HR, Pro S & $-11.7 \mathrm{a}$ & $5.6 \mathrm{a}$ & $72.8 \mathrm{a}$ & $91.6 \mathrm{a}$ & $100.0 \mathrm{a}$ \\
\hline$X Q-46$ & & $-4.5 b$ & $8.2 \mathrm{a}$ & $76.4 \mathrm{a}$ & $89.4 \mathrm{a}$ & $100.0 \mathrm{a}$ \\
\hline XY-82 & & $-12.6 \mathrm{a}$ & $7.7 \mathrm{a}$ & $73.5 \mathrm{a}$ & $91.3 \mathrm{a}$ & $100.0 \mathrm{a}$ \\
\hline
\end{tabular}

\footnotetext{
$\overline{\mathrm{X}}$ Thi HR = highly resistant to thiophanate-methyl; Die $\mathrm{R}=$ resistant to diethofencarb; Pro LR = lowly resistant to procymidone; Pro $\mathrm{S}=$ sensitive to procymidone

${ }^{Y}$ Mean values with the same letters within the same column were not significantly different based on LSD tests at $P=0.05$

${ }^{\mathrm{Z}}$ Thi $=70 \%$ thiophanate-methyl WP at a concentration of $100 \mathrm{mg}$ ai $1^{-1}$, Thi + Die $=70 \%$ thiophanate-methyl WP at a concentration of

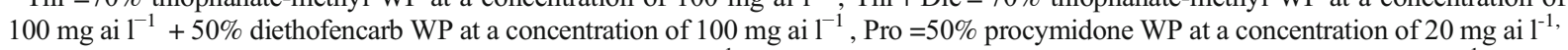
Azo $10=25 \%$ azoxystrobin SC at concentrations of $10 \mathrm{mg} \mathrm{ai}^{-1}$, Azo $20=25 \%$ azoxystrobin SC at concentrations of $20 \mathrm{mg}$ ai $1^{-1}$. Water containing Tween 80 (without any fungicide) was used as the control
} 
Fig. 2 Control efficacy (\%) of azoxystrobin at different concentrations against A. alternata on tobacco leaves applied at $48 \mathrm{~h}$ after inoculation, and $0 \mathrm{~h}, 12 \mathrm{~h}$, and $24 \mathrm{~h}$ before inoculation. Mean values with the same letters within the same concentration were not significantly different based on LSD tests at $P=0.05$

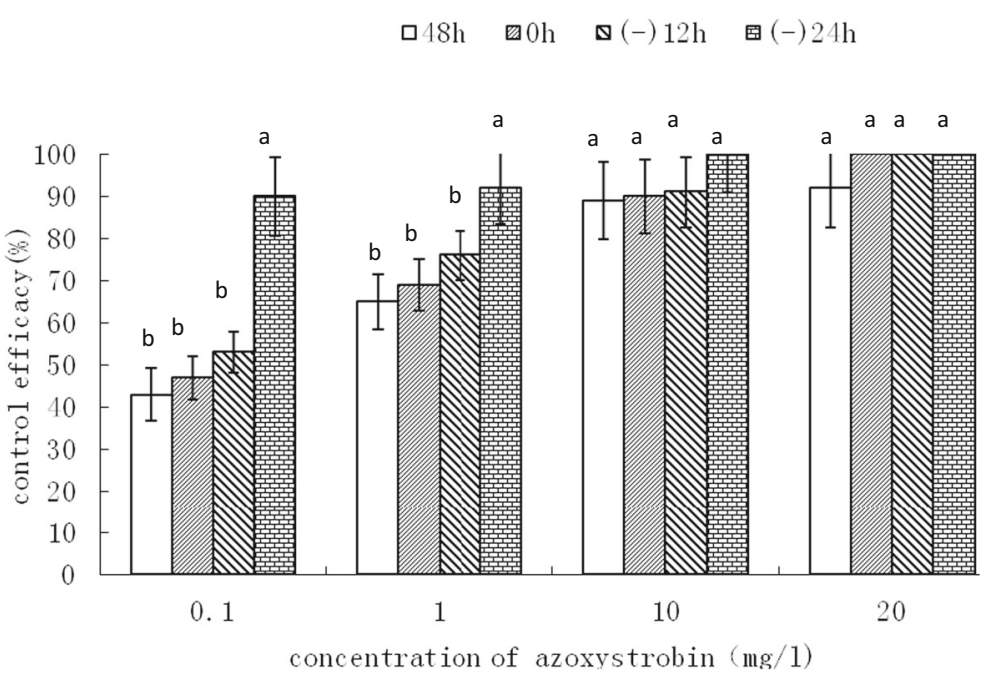

$15.63 \mathrm{mg}^{-1}$. SHAM exhibited significant synergism with azoxystrobin in mycelial growth inhibition in A. alternata, as indicated by the mean $\mathrm{EC}_{50}$ ratio $\left(\mathrm{EC}_{50}\right.$ ratio $\left.=\mathrm{EC}_{50}(-\mathrm{SHAM}) / \mathrm{EC}_{50}(+\mathrm{SHAM})\right)$ of 5.27 (Table 3 ).

Sensitivity baseline of the A. alternata to azoxystrobin

The $\mathrm{EC}_{50}$ value of azoxystrobin was determined for each single-spored isolate of A. alternata from the 28 tobacco fields in Guizhou Province, which is one of the most important tobacco production regions in

Table 3 Inhibitory activity of azoxystrobin on the mycelial growth of A. alternata from tobacco

\begin{tabular}{|c|c|c|c|c|}
\hline \multirow[t]{2}{*}{ Isolates } & \multirow[t]{2}{*}{ Phenotypes ${ }^{\mathrm{X}}$} & \multicolumn{2}{|c|}{$\mathrm{EC}_{50}\left(\mathrm{mg} \mathrm{l}^{-1}\right)$} & \multirow{2}{*}{$\begin{array}{l}\mathrm{EC}_{50}(-\mathrm{SHAM}) / \\
\mathrm{EC}_{50}(+\mathrm{SHAM})\end{array}$} \\
\hline & & -SHAM & + SHAM $^{\mathrm{Z}}$ & \\
\hline XQ-3 & Pro LR & $88.18 b^{Y}$ & $21.42 \mathrm{a}$ & 4.12 \\
\hline XQ-7 & & $112.9 \mathrm{a}$ & $20.16 \mathrm{a}$ & 5.60 \\
\hline XY-5 & & $39.81 \mathrm{~d}$ & $7.94 \mathrm{~b}$ & 5.01 \\
\hline XY-13 & & $52.12 \mathrm{c}$ & $9.13 b$ & 5.71 \\
\hline XY-25 & Pro $\mathrm{S}$ & $62.23 \mathrm{c}$ & $9.74 b$ & 6.39 \\
\hline XQ-46 & & $90.36 \mathrm{~b}$ & $21.57 \mathrm{a}$ & 4.19 \\
\hline XY-82 & & $114.21 \mathrm{a}$ & $19.44 \mathrm{a}$ & 5.88 \\
\hline
\end{tabular}

\footnotetext{
$\overline{\mathrm{X}}$ Pro LR $=$ lowly resistant to procymidone; Pro $\mathrm{S}=$ sensitive to procymidone

${ }^{Y}$ Mean values with the same letters within the same column were not significantly different based on LSD tests at $P=0.05$

$\mathrm{Z}$-SHAM and + SHAM represent the absence and presence of SHAM at $50 \mathrm{mg} \mathrm{l}^{-1}$, respectively
}

China. The $\mathrm{EC}_{50}$ values of isolates that had been collected from different sampling sites during 2014 and 2015 were analyzed. There were no significant variations in the sensitivity of the A. alternata populations between the two sites, $\mathrm{XQ}$ and $\mathrm{XY}$. The average $\mathrm{EC}_{50}$ value for the 151 isolates was $0.49 \pm 0.22$ (Mean $\pm \mathrm{SD}$ ) $\mathrm{mg} \mathrm{l}^{-1}$. The factor of the $\mathrm{EC}_{50}$ value between the most sensitive $\left(0.11 \mathrm{mg} \mathrm{l}^{-1}\right)$ and least sensitive $\left(2.47 \mathrm{mg} \mathrm{l}^{-1}\right)$ isolate was 22.5 (Fig. 3).

In vitro selection for azoxystrobin resistance

Both the UV irradiation and A. tumefaciens-mediated selection tests were repeated more than 30 times. No single colonies grew on the plates containing $10 \mathrm{mg}^{-1}$ azoxystrobin and $50 \mathrm{mg}^{-1}$ SHAM. Azoxystrobin-resistant mutants were thus not obtained through numerous inductions.

\section{Discussion}

Resistance to dicarboximide fungicides (FRAC 2) has previously been attributed to point mutations in the $O S 1$ gene of plant-pathogenic fungi. However, the exact molecular mechanisms of the dicarboximide resistance have not been fully elucidated, and thus other yet unknown mechanisms may exist (Firoz et al. 2016; Leroux et al. 2002; Ma and Michailides 2004, 2005; Sang et al. 2017). In the present study, six isolates collected from Xinquan and three isolates from Xinyi that showed LR to procymidone, an extensively applied dicarboximide 


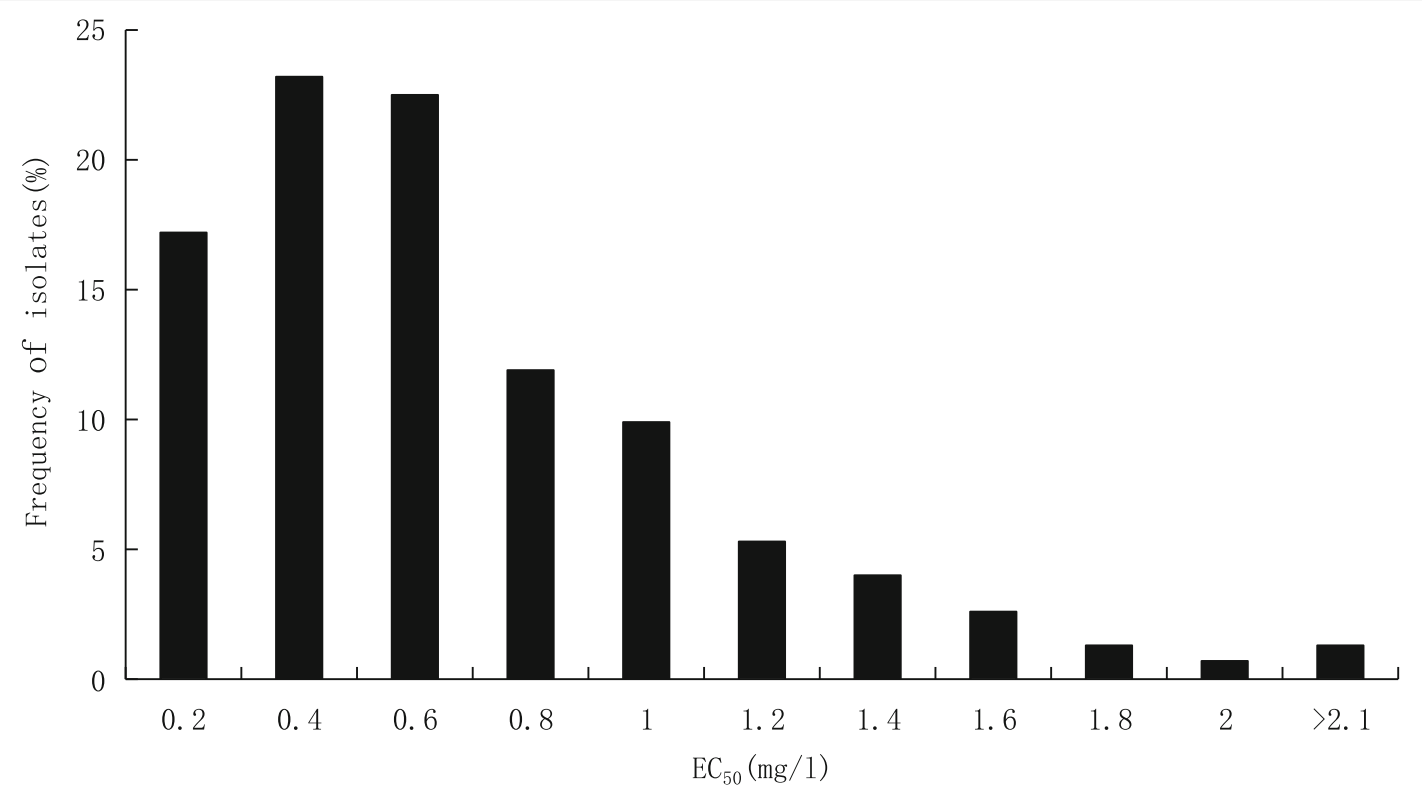

Fig. 3 Distribution of $\mathrm{EC}_{50}$ values of the A. alternata population $(n=151)$ from tobacco plants to azoxystrobin during spore germination in the presence of $50 \mathrm{mg}^{-1} \mathrm{SHAM}$

fungicide, were detected with a frequency of $6.0 \%$. However, no mutation was found in the $\mathrm{OS} 1$ of all nine procymidone-LR isolates. In the tobacco plants, procymidone demonstrated significantly higher control efficacy against the procymidone-S isolates than the LR isolates. The results suggested that the LR isolates exhibited at least some resistance to procymidone in plants, and thus the molecular mechanisms involved in procymidone resistance in A. alternata from tobacco require further investigation.

The loss of control of TBS when using benzimidazole fungicides (FRAC 1) in China can be directly attributed to the occurrence of high frequency HR sub-population in the tobacco fields. A combination of thiophanate-methyl and diethofencarb is commonly used to control Ben R1 isolates in other plant-pathogenic fungi (Lin et al. 2016; Nenad et al. 2015; Walker et al. 2013) but may not be an efficient method for TBS control in China due to dual resistance. In other fungi worldwide, Ben R2 isolates exhibiting resistance to benzimidazole fungicides and diethofencarb are commonly observed in fields following the application of a mixture of "a benzimidazole fungicide+ diethofencarb" (Lin et al. 2016; Walker et al. 2013). In B. cinerea, the frequency of Ben R2 harboring the F200Y mutation rapidly decreases due to a fitness penalty if the usage of the mixture is stopped (Walker et al.
2013). Benzimidazole fungicides have been used to control TBS in Guizhou Province for more than 15 years, while the mixture of carbendazim (or thiophanate-methyl) and diethofencarb has only been recently introduced (Dong et al. 2009; Zhang et al. 2013a, b). Further study is required to explain the basis for the dominance of isolates exhibiting double-resistance to benzimidazole fungicide and diethofencarb in tobacco fields. Interestingly, it was observed that thiophanate-methyl promoted TBS lesion formation of these double-resistant isolates in the tobacco leaves. The stimulation of the pathogenesis of S. sclerotiorum isolates that are HR to benzimidazole chemicals by carbendazim has been reported (Di et al. 2016). This effect of a compound on the fungus that is resistant to this class of chemical will possibly render plant disease control more challenging in the future. This study indicated that benzimidazole fungicides and the mixture of benzimidazole fungicide with diethofencarb should not be adopted for the control of TBS.

Benzimidazole fungicides severely affect cell division through binding microtubular ( $\mathrm{Ma}$ and Michailides 2005). The single-point mutations that appear to be restricted to codons 50, 198, 200, and 240 in the $\beta$-tubulin encoding gene are responsible for resistance development (Albertini et al. 1999; Davidson et al. 2006; Koenraadt et al. 1992; Ma and 
Michailides 2005; Maymon et al. 2006; McKay et al. 1998; Nenad et al. 2015; Panebianco et al. 2015; Torres-Calzada et al. 2015). Only a single F167Y mutation was observed in all of the thiophanatemethyl HR isolates of A. alternata from tobacco. The mutation at the 167 th codon has only been reported to cause benzimidazole resistance in a few fungi, such as Fusarium graminearum, the pathogen of wheat scab (Chen et al. 2007; Liu et al. 2013).

In the tobacco plant tests, we found that azoxystrobin, a $\mathrm{Q}_{\mathrm{O}} \mathrm{I}$ fungicide (FRAC 11), showed strong activity against $A$. alternata, and no crossresistance was found between azoxystrobin and thiophanate-methyl, procymidone, or diethofencarb. Further assessment indicated that azoxystrobin had excellent protective activity against TBS disease caused by A. alternata, while the curative activity against A. alternata in the tobacco plants depended on the treatment concentration. Over the past decade, QoI fungicides have become the major class of fungicides for the management of Alternaria in other hosts (Karaoglanidis et al. 2011; Vega et al. 2012). The monitoring of application strategies and resistance development is crucial for a novel fungicide that is adopted to control a plant pathogen. Furthermore, the establishment of baseline sensitivity is a prerequisite for performing this task (Russell 2004). In this study, A. alternata populations from tobacco fields where $\mathrm{Q}_{\mathrm{O}} \mathrm{Is}$ had not been used prior to sampling were used to establish the sensitivity baseline to azoxystrobin. Conidial germination of A. alternata from tobacco was more sensitive to azoxystrobin than mycelial growth. No resistant sub-population was observed in the tobacco isolates of A. alternata. Therefore, the mean $\mathrm{EC}_{50}$ value of $0.49 \pm 0.22 \mathrm{mg} \mathrm{l}^{-1}$ could be used as the baseline to monitor the shifts in azoxystrobin sensitivity in the future. It is difficult to obtain resistant mutants of A. alternata in vitro, however, azoxystrobin can not be considered to have a low resistance risk. Resistance to QoIs, a group of fungicides that are susceptible to resistance development (Standish et al. 2016; Mikaberidze et al. 2014; Vega et al. 2012), has occurred in many plant pathogens (Drabesova et al. 2013; Mikaberidze et al. 2014; Vega et al. 2012). Therefore, the sensitivity of A. alternata from tobacco to QoIs should be carefully monitored following their applications for the control of TBS. Furthermore, it is recommended that the azoxystrobin be restricted in use frequency and alternated or mixed with fungicides of other FRAC groups, such as procymidone, to manage TBS and delay the resistance development.

Acknowledgments This research was partially supported by the NSFC (No. 31360448) and cooperative program of the Guizhou Academy of Tobacco Science. We would like to thank LetPub (www.letpub.com) for providing linguistic assistance during the preparation of this manuscript.

\section{Compliance with ethical standards}

Conflict of interest The authors declare that they have no conflict of interest.

\section{References}

Albertini, C., Gredt, M., \& Leroux, P. (1999). Mutations of the $\beta$ tubulin gene associated with different phenotypes of benzimidazole resistance in the cereal eyespot fungi Tapesia yallundae and Tapesia acuformis. Pesticide Biochemistry and Physiology, 64, 17-31.

Avenot, H., Simoneau, P., Iacomi-Vasilescu, B., \& BatailleSimoneau, N. (2005). Characterization of mutations in the two-component histidine kinase gene $A b N I K 1$ from Alternaria brassicicola that confer high dicarboximide and phenylpyrrole resistance. Current Genetics, 47, 234-243.

Avila-Adame, C., \& Köller, W. (2003). Impact of alternative respiration and target-site mutations on responses of germinating conidia of Magnaporthe grisea to Qo-inhibiting fungicides. Pest Management Science, 59, 303-309.

Bartlett, D. W., Clough, J. M., Godwin, J. R., Hall, A. A., Hamer, M., \& Parr-Dobrzansk, B. (2002). The strobilurin fungicides. Pest Management Science, 58, 649-662.

Chen, C. J., Wang, J. X., Luo, Q. Q., \& Yuan, S. K. (2007). Characterization and fitness of carbendazim-resistant strains of Fusarium graminearum (wheat scab). Pest Management Science, 63, 1201-1207.

Chen, Y., Yang, X., Yuan, S. K., Li, Y. F., Zhang, A. F., Yao, J., \& Gao, T. C. (2015). Effect of azoxystrobin and kresoximmethyl on rice blast and rice grain yield in China. Annals of Applied Biology, 166, 434-443.

Cheng, D. D., Jia, Y. J., Gao, H. Y., Zhang, L. T., Zhang, Z. S., Xue, Z. C., \& Meng, Q. W. (2011). Characterization of the programmed cell death induced by metabolic products of Alternaria alternata in tobacco BY-2 Cell. Physiologia Plantarum, 141, 117-129.

Davidson, R. M., Hanson, L. E., Franc, G. D., \& Panella, L. (2006). Analysis of $\beta$-tubulin gene fragments from benzimidazole-sensitive and -tolerant Cercospora beticola. Journal of Phytopathology, 154, 321-328.

Di, Y. L., Lu, X. M., Zhu, Z. Q., \& Zhu, F. X. (2016). Time course of carbendazim stimulation on pathogenicity of Sclerotinia sclerotiorum indicates a direct stimulation mechanism. Plant Disease, 100, 1454-1459. 
Dong, X. C., Zhang, Z. Q., Liu, L. M., \& Zhang, H. J. (2009). Comparison on the control effects of 6 fungicides on the main diseases in tobacco in its late growth stage. Journal of Anhui Agricultural Science, 37, 9032-9037.

Drabesova, J., Ryanek, P., Brunner, P., McDonald, B. A., \& Croll, D. (2013). Population genetic structure of Mycosphaerella graminicola and Quinone outside inhibitor (Qo I) resistance in the Czech Republic. European Journal of Plant Pathology, 135, 211-224.

Estep, L. K., Torriani, S. F., Zala, M., Anderson, N. P., Flowers, M. D., McDonald, B. A., Mundt, C. C., \& Brunner, P. C. (2015). Emergence and early evolution of fungicide resistance in north American populations of Zymoseptoria tritici. Plant Pathology, 64, 961-971.

Fairchild, K. L., Miles, T. D., \& Wharton, P. S. (2013). Assessing fungicide resistance in populations of Alternaria in Idaho potato fields. Crop Protection, 49, 31-39.

Fan, Z., Yang, J. H., Fan, F., Luo, C. X., \& Schnabel, G. (2015). Fitness and competitive ability of Alternaria alternata field isolates with resistance to SDHI, QoI, and MBC fungicides. Plant Disease, 99, 1744-1750.

Firoz, J., Xiao, X., Zhu, F. X., Fu, Y. P., Jiang, D. H., Schnabel, G., \& Luo, C. X. (2016). Exploring mechanisms of resistance to dimethachlone in Sclerotinia sclerotiorum. Pest Management Science, 72, 770-779.

Karaoglanidis, G. S., Luo, Y., \& Michailides, T. J. (2011). Competitive ability and fitness of Alternaria alternata isolates resistant to QoI fungicides. Plant Disease, 95, 178-182.

Koenraadt, H., Somerville, S. C., \& Jones, A. L. (1992). Characterization of mutations in the beta-tubulin gene of benomyl-resistant field strains of Venturia inaequalis and other plant pathogenic fungi. Phytopathology 82, 13481354.

Leroux, P., Fritz, R., Debieu, D., Albertin, C., Lanen, C., Bach, J., Gredt, M., \& Chapeland, F. (2002). Mechanisms of resistance to fungicides in field strains of Botrytis cinerea. Pest Management Science, 58, 876-888.

Li, Y. J., Chen, H. M., \& Yang, Y. (2002). Evaluations of fungicides controlling of tobacco brown spot in fields. Pesticides, $41,31-33$.

Lin, T., Xu, X. F., Dai, D. J., Shi, H. J., Wang, H. D., \& Zhang, C. Q. (2016). Differentiation in development of benzimidazole resistance in Colletotrichum gloeosporioides complex populations from strawberry and grape hosts. Australasian Plant Pathology, 36, 73-77.

Liu, S. M., Duan, Y. B., Ge, C. Y., Chen, C. J., \& Zhou, M. G. (2013). Functional analysis of the $\beta 2$-tubulin gene of Fusarium graminearum and the $\beta$-tubulin gene of Botrytis cinerea by homologous replacement. Pest Management Science, 69, 582-588.

Lucas, G. B. (1975). Diseases of tobacco, 3rd edn. Biological Consulting Associates, Raleigh.

Ma, Z. H., \& Michailides, T. J. (2004). Characterization of iprodione-resistant Alternaria isolates from pistachio in California. Pesticide Biochemistry and Physiology, 80, 75-84.

Ma, Z. H., \& Michailides, T. J. (2005). Advances in understanding molecular mechanisms of fungicide resistance and molecular detection of resistant genotypes in phytopathogenic fungi. Crop Protection, 24, 853-863.
Ma, Z. H., Yoshimura, M. A., Holtz, B. A., \& Michailides, T. J. (2005). Characterization and PCR-based detection of benzimidazole-resistant isolates of Monilinia laxa in California. Pest Management Science, 61, 449-457.

Maymon, M., Zveibil, A., Pivonia, S., Minz, D., \& Freeman, S. (2006). Identification and characterization of benomylresistant and -sensitive populations of Colletotrichum gloeosporioides from Statice (Limonium spp.). Phytopathology, 96, 542-548.

McKay, G., Egan, J. D., Morris, E., \& Brown, A. E. (1998). Identification of benzimidazole resistance in Cladobotryum dendroides using a PCR-based method. Mycological Research, 102, 671-676.

Mikaberidze, A., McDonald, B. A., \& Bonhoeffer, S. (2014). Can high-risk fungicides be used in mixtures without selecting for fungicide resistance? Phytopathology, 104, 324-331.

Nenad, T., Anja, M., Rade, S., Milana, M., Jelena, J., Ivo, T., \& Jelena, B. (2015). Occurrence of Cercospora beticola populations resistant to benzimidazoles and demethylationinhibiting fungicides in Serbia and their impact on disease management. Crop Protection, 75, 80-87.

Nishimura, S., \& Kohmoto, K. (1983). Host-specific toxins and chemical structures from Alternaria species. Annual Review of Phytopathology, 21, 87-116.

Panebianco, A., Castello, I., Cirvilleri, G., Perrone, G., Epifani, F., Ferrara, M., Polizzi, G., Walters, D. R., \& Vitale, A. (2015). Detection of Botrytis cinerea field isolates with multiple fungicide resistance from table grape in Sicily. Crop Protection, 77, 65-73.

Pitt, W. M., Sosnowski, M. R., Huang, R., Qiu, Y., Steel, C. C., \& Savocchia, S. (2012). Evaluation of fungicides for the management of Botryosphaeria canker of grapevines. Plant Disease, 96, 1303-1308.

Russell, P. E. (2004). Sensitivity baselines in fungicide resistance research and management. FRAC Monograph 3, CropLife International, Brussels. Available on line at www. frac. Info.

Sang, H., Popko, J. T., Chang, J. T., \& Jung, G. (2017). Molecular mechanisms involved in qualitative and quantitative resistance to the dicarboximide fungicide iprodione in Sclerotinia homoeocarpa field isolates. Phytopathology, 107, 198-207.

Shew, H. D., \& Lucas, G. B. (1991). Compendium of tobacco diseases. American Phytopathological Society, St. Paul.

Standish, J. R., Avenot, F. H., Brenneman, T. B., \& Stevenson, K. L. (2016). Location of an intron in the cytochrome $b$ gene indicated reduced risk of QoI fungicide resistance in Fusicaldium effusum. Plant Disease, 100, 2294-2298.

Stavely, J. R. (1975). Relationship of postinoculation leaf wetness to initiation of tobacco brown spot. Phytopathology, 65, 897-901.

Torres-Calzada, C., Tapia-Tussel, R., Higuera-CiaparaI, M. R., Nexticapan-Garcez, A., \& Perez-Brito. (2015). Sensitivity of Colletotrichum truncatum to four fungicides and characterization of thiabendazole-resistant isolates. Plant Disease, 99, 1590-1595.

Vega, B., Liberti, D., Harmon, P. F., \& Dewdney, M. M. (2012). A rapid resazurin-based microtiter assay to evaluate QoI sensitivity for Alternaria alternata isolates and their molecular characterization. Plant Disease, 96, 1262-1270. 
Vitale, A., Panebianco, A., \& Polizzi, G. (2016). Baseline sensitivity and efficacy of fluopyram in Botrytis cinerea from table grape in Italy. Annals of Applied Biology, 169, 36-45.

Walker, A. S., Micoud, A., Rémuson, F., Grosman, J., Gredt, M., \& Leroux, P. (2013). French vineyards provide information that opens ways for effective resistance management of Botrytis cinerea (grey mould). Pest Management Science, 69, 667-678.

Xu, H. J., Wang, Y. J., Zhao, P. B., Zhang, Y. B., Xu, R. Y., \& Li, D. C. (2011). A cAMP-dependent protein kinase gene, aapkl, is required for mycelia growth, toxicity and pathogenicity of Alternaria alternata on tobacco. Journal of Phytopathology, 159, 208-216.

Zhang, C. Q., Liu, Y. H., \& Zhu, G. N. (2010). Detection and characterization of benzimidazole resistance of Botrytis cinerea in greenhouse vegetables. European Journal of Plant Pathology, 126, 509-515.

Zhang, C. Q., Liu, Y. H., Ding, L., \& Zhu, G. N. (2011). Shift of sensitivity of Botrytis cinerea to azoxystrobin in greenhouse vegetables before and after exposure to the fungicide. Phytoparasitica, 39, 293-302.

Zhang, C., Wu, H., Li, X., Shi, H., Wei, F., \& Zhu, G. (2013a). Baseline sensitivity of natural populations and resistance of mutants of Xanthomonas oryzae pv. oryzae to a novel bactericide, zinc thiazole. Plant Pathology, 62, 1378-1383.

Zhang, W. M., Zhang, C. Q., Zhou, Z. B., \& Deng, Y. (2013b). Field efficacy evaluation of different fungicides in controlling Alternaria alternata on tobacco. Biological Disaster Science, 36, 288-290. 